\title{
BMJ Open Determinants of imbalanced sex ratio at birth in Nepal: evidence from secondary analysis of a large hospital-based study and nationally-representative survey data
}

\author{
Elina Pradhan, ${ }^{1}$ Erin Pearson, ${ }^{2}$ Mahesh Puri, ${ }^{3}$ Manju Maharjan, ${ }^{2}$ \\ Dev Chandra Maharjan, ${ }^{3}$ Iqbal Shah ${ }^{4}$
}

To cite: Pradhan E, Pearson E, Puri M, et al. Determinants of imbalanced sex ratio at birth in Nepal: evidence from secondary analysis of a large hospital-based study and nationally-representative survey data. BMJ Open 2019;9:e023021. doi:10.1136/ bmjopen-2018-023021

- Prepublication history and additional material for this paper are available online. To view these files, please visit the journal online (http://dx.doi. org/10.1136/bmjopen-2018023021).

Received 23 March 2018 Revised 4 December 2018 Accepted 19 December 2018

Check for updates

(C) Author(s) (or their employer(s)) 2019. Re-use permitted under CC BY-NC. No commercial re-use. See rights and permissions. Published by BMJ.

${ }^{1}$ The World Bank Group, Washington, District of Columbia, USA

${ }^{2}$ IPAS, Chapel Hill, North

Carolina, USA

${ }^{3}$ Center for Research on Environment, Population and Health Activities, Kathmandu, Nepal

${ }^{4}$ Harvard T.H. Chan School of Public Health, Boston, Massachusetts, USA

Correspondence to Dr Elina Pradhan; epradhan@mail.harvard.edu

\section{ABSTRACT}

Objectives To quantify sex ratios at births (SRBs) in hospital deliveries in Nepal, and understand the sociodemographic correlates of skewed SRB. Skewed SRBs in hospitals could be explained by sex selective abortion, and/or by decision to have a son delivered in a hospitalincreased in -utero investments for male fetus. We use data on ultrasound use to quantify links between prenatal knowledge of sex, parity and skewed SRBs.

Design Secondary analysis of: (1) de-identified data from a randomised controlled trial, and (2) $2011 \mathrm{Nepal}$ Demographic and Health Survey (NDHS).

Setting Nepal.

Participants (1) 75428 women who gave birth in study hospitals, (2) NDHS: 12674 women aged 15-49 years.

Outcome measures SRB, and conditional SRB of a second child given first born male or female were calculated. Results Using data from 75428 women who gave birth in six tertiary hospitals in Nepal between September 2015 and March 2017, we report skewed SRBs in these hospitals, with some hospitals registering deliveries of 121 male births per 100 female births. We find that a nationally representative survey (2011 NDHS) reveals no difference in the number of hospital delivery of male and female babies. Additionally, we find that: (1) estimated SRB of second-order births conditional on the first being a girl is significantly higher than the biological SRB in our study and (2) multiparous women are more likely to have prenatal knowledge of the sex of their fetus and to have male births than primiparous women with the differences increasing with increasing levels of education.

Conclusions Our analysis supports sex-selective abortion as the dominant cause of skewed SRBs in study hospitals. Comprehensive national policies that not only plan and enforce regulations against gender-biased abortions and, but also ameliorate the marginalised status of women in Nepal are urgently required to change this alarming manifestation of son preference.

Trial registration number NCT02718222.

\section{BACKGROUND}

Sex ratios at birth (SRBs), that is, number of male births per 100 female births, have long

\section{Strengths and limitations of this study}

- This is the first paper that explicitly quantifies associations between ultrasound access and skewed sex ratios at birth (SRBs).

- A strength of the study is that the analysis presented is based on a large sample - the primary sample is about $20 \%$ of all births in Nepal that happened during the study period.

- However, a limitation could be that this primary sample is not representative at the population level as it is derived from a hospital-based study.

- The study adjusts for potential socioeconomic and time-varying confounders and presents SRBs adjusted for age, ethnicity, region, hospital fixed effects and month fixed effects.

- Another potential limitation is that women's report of abortion history, which is a mediating variable reported, could suffer from reporting bias.

been shown to be skewed in China, South Korea, some states of India and in some other East and South Asian and North African countries, but evidence suggests that since the 1990s, skewed sex ratios are emerging in other Asian countries such as Pakistan and Vietnam. ${ }^{2}$ The biologically-normal SRB ranges from 102 to 107 males per 100 females with 105 as the most common figure, ${ }^{34}$ but in India, the national SRB is 109 compared with 120 in China, ${ }^{1}$ indicating that significantly more boys are being born than girls in these two countries, especially in China. As ultrasound technology has become more widely available in Asia, sex ratios have become more skewed. ${ }^{156}$ When societies with strong son preference transition to low fertility, the desire to have male offspring becomes more acute and access to this technology can facilitate its realisation. Couples may use 
ultrasound and other prenatal diagnostic tests for sex-selective abortion, though only about $11 \%-27 \%$ of all ultrasound users across states in India were using ultrasound for sex-selective abortion between 1998 and 1999 when ultrasound was first becoming more widely available. ${ }^{5}$ Given the trajectory of increasing sex ratios over time in Asia, it is possible that the ultrasound misuse for sex-selective abortion has increased as well as social pressure for sons has intensified with shrinking family sizes. Bhat and Zavier ${ }^{7}$ found that wealthier, more educated women in India had greater access to technology such as ultrasound, but ultrasound misuse for sex-selective abortion was more highly associated with region and sex composition of children already born. ${ }^{57}$ Another study examining birth patterns of Indian migrants to Canada also found skewed sex ratio of higher parity births if the mothers only had girls, and furthermore, the skewed SRBs were associated with history of induced abortions. ${ }^{8}$

In Nepal, son preference has been documented, but it has primarily manifested in women's contraceptive use and preferential care for male children, including more and higher quality food and better medical care, consistent with the 'femineglect' in health and education seen elsewhere in Asia. ${ }^{19} 10$ As a result, older studies demonstrated higher under-five female compared with male mortality in Nepal due to preferential treatment and medical care for sons but did not demonstrate skewed SRBs. ${ }^{19}$ More recent studies have demonstrated that conditional sex ratios, the sex ratio for second-born child when the first-born child was female, became skewed after abortion law was liberalised in 2002. ${ }^{11}$ Though sex-determination tests and sex-selective abortion are illegal in Nepal, punishable by imprisonment from 3 months to 6 months, ${ }^{12}{ }^{13}$ evidence suggests that it does occur. ${ }^{11} 14$ Abortion providers report difficulty ascertaining whether families are seeking abortion for sex-selection purposes and fear that women will resort to unsafe abortion if they are under pressure to bear sons but unable to access safe abortion services. ${ }^{14}$ A comparison of two districts in Nepal found that many conditions led to higher SRB in one district compared with the other, including greater access to ultrasound due to more facilities offering diagnostic services and greater purchasing power, less enforcement of the law barring sex-selective abortion, desire for fewer children and fewer community-based programmes on gender equity. ${ }^{12}$

This is the first paper that shows highly skewed sex ratios from facility births in Nepal and explicitly quantifies associations between ultrasound access and skewed SRBs. Women attending the facilities in the study generally have access to high-quality care, including access to ultrasound technology, which is available in most study hospitals. Ultrasound may act on SRBs in these hospitals through two pathways: (1) sex-selective abortion or (2) increased investment in delivery care for male babies. The present study explores potential pathways leading to skewed sex ratios in Nepal's largest hospitals by comparing estimates from the hospital-based sample with high access to ultrasound services to population-based estimates from Nepal's 2011 Demographic and Health Survey. ${ }^{15}$ The main objective is, therefore, to examine if skewed SRB prevail on hospital deliveries compared with all births in a nationally-representative household survey and the primary pathways leading to such outcome.

\section{DATA AND METHODS}

\section{A study design}

We assess SRB by geographic divisions and sociodemographic background characteristics of women using data from a multisite facility-based survey of postpartum women in six of the largest hospitals in Nepal and from a population-based nationally-representative survey (Nepal Demographic and Health Survey [NDHS]).

\section{Data}

The 2011 NDHS included 12674 ever-married women aged 15-49 years, and the sample for the analysis included 4047 births in the 5 years preceding the survey. The longitudinal data come from a hospital-based survey conducted as part of an evaluation of postpartum contraceptive services in six hospitals in Nepal. The six hospital sites were: Bharatpur Regional Hospital, B.P. Koirala Institute of Health Sciences (BPKIHS), Koshi Zonal Hospital, Lumbini Zonal Hospital, Western Regional Hospital and Bheri Zonal hospital. These sites span all the way from midwestern development zone to the eastern development zone; two hospitals are in the hilly region and four in the Terai. There are also some differences in the ethnic groups served by these hospitals (online supplementary appendix figure 1$)-27 \%$ of women who gave birth in Koshi Zonal hospital are so called 'untouchables' (Dalits) versus only 9\% in BPKIHS; $48 \%$ of women served by BPKIHS are indigenous group (Janajaatis) versus $25 \%$ in Bheri Zonal.

Women were enrolled in the study over a period of 18 months and completed a short questionnaire after delivery, before they are discharged from the hospital. A sample of those enrolled in the study were also approached for follow-up questionnaires at 9 months and 18 months postpartum. Inclusion criteria are that women have had a live birth, delivered in one of the six study hospitals, and reside in Nepal. Detailed study protocol has been published. ${ }^{16}$

Out of a total of 75897 women eligible for the study in the enrolment period (September 2015-March 2017), $75587(99.6 \%)$ consented to be interviewed, and interviews were conducted prior to discharge from hospital after delivery. The full sample used in this study constitutes 75428 women who consented to answering questions pertaining to variables analysed in this paper.

The 9-month survey captures information not available in the 2011 NDHS, including a detailed assessment of ultrasound use during the recent pregnancy and previous pregnancies. The 9-month survey also captures the sex composition of all children born, and conditional sex 
ratios for second-born child given the sex of the first-born child will be calculated and compared with our estimates from the 2011 NDHS. This 9-month follow-up sample includes 14015 women, with follow-up rate of $57.4 \%$.

\section{Methods}

Sex ratios were calculated for all births by dividing the total number of boys born by the total number of girls born, and multiplying by 100 . Conditional sex ratios were calculated for second-order births. Conditional sex ratios assess the ratio of second-order boys to second-order girls given the sex of the first child. Conditional sex ratios are often used to provide evidence for sex-selective abortion as women who want or are pressured to have a son are likely to take action at parity two, especially in the context of shrinking family size. ${ }^{11} 1718$ A sex ratio or conditional sex ratio of greater than 100 indicates more boys born compared with girls, and a sex ratio of less than 100 indicates more girls born compared with boys, while the biological ratio is estimated at 105 male-to-female births. The claim of skewed SRB is made when the SRB calculated is statistically different from the biological SRB.

Linear regression models with hospital and month fixed effects are used to estimate the association between women's sociodemographic characteristics and male birth. The hospital and month fixed effects control for any hospital-specific or time-specific changes to the outcomes unrelated to the intervention, including any potential impact of the April 2015 earthquakes in Nepal. ${ }^{19}$ Equation (1) below represents the multivariate model, where we interact women's education and parity to understand any multiplier effects of these two variables on male preference for woman $\mathrm{i}$, hospital $\mathrm{h}$ and month $\mathrm{t}$. We also control for region, ethnicity, woman's age, abortion history $\left(X_{i}\right)$, hospital fixed effects and month fixed effects.

$$
\begin{aligned}
\text { male birth }_{\text {iht }}= & \alpha+\beta \text { schooling }_{i}+\psi \text { Parity }_{i}+\boldsymbol{\omega}_{\text {schooling }} * \text { Parity }_{i} \\
& +\gamma X_{i}+\sum_{h=1}^{5} \delta_{h} H_{h}+\sum_{t=1}^{11} \tau_{t} T_{t}+\epsilon_{i h t}
\end{aligned}
$$

Outcomes for women who visit the same hospitals are likely to be correlated with each other. For example, social norms about family size and son preference could be localised in a geographic area. Hence, inference needs to be corrected for this potential correlation in each hospital cluster. Since we only have six hospitals or six clusters in our study, the standard cluster robust variance estimator can over-reject the null hypothesis. ${ }^{20}$ We use the wild cluster bootstrap method with six-point bootstrap weight distribution to estimate the statistical significance of the effect size for all regression models. ${ }^{21-23}$

We use questions asked in our 9-month follow-up on a subset of women randomly selected (among women who lived within 24 hours of travel time from the hospital) at the time of enrolment to understand any links between ultrasound prevalence, knowing the sex of the child before birth and male child born at the study hospital. Similar to model 1, equations 2 and 3 below are the models we use to understand if any of women's sociodemographic characteristics are linked with ultrasound performed during antenatal period of the current birth and if the mother reports knowledge of sex of the child before birth.

$$
\begin{aligned}
\text { ultrasound }_{i}= & \alpha+\beta \text { schooling }_{i}+\psi \text { Parity }_{i}+\text { w }_{\text {schooling }} * \text { Parity }_{i} \\
& +\gamma X_{i} \sum_{h=1}^{5} \delta_{h} H_{h}+\sum_{t=1}^{11} \tau_{t} T_{t}+\epsilon_{i h t}
\end{aligned}
$$

know_sex_before_birth $_{i}=\alpha+\beta$ schooling $_{i}+\psi$ Parity $_{i}+\boldsymbol{\omega}_{\text {schooling }} *$ Parity

$$
+\gamma X_{i} \sum_{h=1}^{5} \delta_{h} H_{h}+\sum_{t=1}^{11} \tau_{t} T_{t}+\epsilon_{i h t}
$$

We then estimate SRBs across mothers' education group, parity and prenatal knowledge of sex, followed by a descriptive picture of conditional SRBs in our study sample and the NDHS sample.

Finally, we perform stepwise linear regression using NDHS data to understand whether boys born in the last five years were more likely to be delivered in hospitals, adjusting for women's sociodemographic characteristics (equation 4). This stepwise method adds each of the potentially relevant socioeconomic variables such as woman's education, parity, age and household wealth tertile $\left(X_{i}\right)$ to the model in addition to male child as explanatory variables and could allow us to identify any models where male births were significantly related to hospital-based deliveries. We could potentially assert the dominance of female feticide as the primary season behind skewed SRBs if we did not find a significant relationship between hospital-based deliveries and male births in these models.

$$
\text { hospital }- \text { based delivery }_{i}=\alpha+\beta \text { male_child }_{i}+\gamma X_{i}+\epsilon_{i}
$$

\section{Patient and public involvement}

The patients and the public were not directly involved in the development of research question, outcome measures or the design of the study. Respondents were women who delivered in the study hospitals and provided consent to participate in the study. The research question was informed by the available data on the status of women in the country and the region, and the results are being incorporated in an early preparation state of Nepal's national strategy to prevent gender-biased sex selection.

\section{RESULTS}

Figure 1 shows the SRB at the six study hospitals. The biological ratio is 105 , and according to Nepal census 2011, the SRB for Nepal is $107 .{ }^{24}$ The ratio of births at the study hospitals is substantially higher than either the biological ratio or the national average. We observe the highest SRB at Western Regional and Bharatpur hospital, 


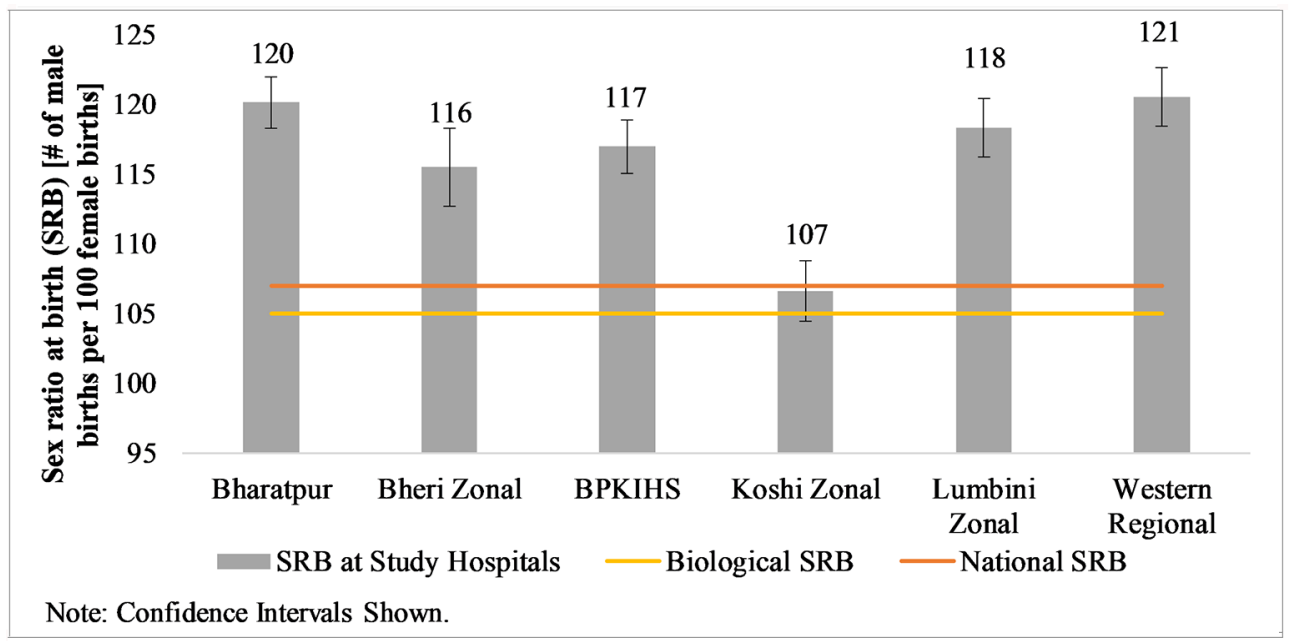

Figure 1 Sex ratio at birth at study hospitals.

with the ratio of 121 and 120 male births per 100 female births, respectively. The SRB in our overall sample is also significantly higher than the national average of 107-we find that 117 male births took place in the study hospitals for every 100 female births.

Table 1, data column 1 presents association between sociodemographic factors with male births in our study hospitals based on model 1 . The descriptive statistics for the variables used in this regression are tabulated in online supplementary appendix table 1 . We find that higher order births are more likely to be male, and a mother with secondary schooling having her third (or higher order) child is 18 percentage points more likely to deliver a male child compared with a woman who has just given birth to her first child. Chhetri women are more likely to have male births compared with Janajaatis. There is significant interaction effect of parity and mother's education when predicting male birth. Furthermore, male birth is not associated with the mother's history of induced abortion.

An estimate of interest is the SRB for education and parity, adjusted for other covariates as shown in equation 1. Figure 2 shows the SRB across women's education and parity predicted from this model. Predicted SRB for women with at least secondary schooling who are giving birth for the first time is 105 male births/100 female births. However, this estimate skews drastically with increasing parity. SRB for women with at least secondary schooling with parity three or higher is estimated at 224 male births per 100 female births.

As discussed previously, there could be two pathways through which deliveries at these large tertiary hospitals are skewed by sex. One could be sex-selective abortion, which will skew the ratio of male births to female births. The other is the selective investment pathway, where families on prior knowledge of the sex of their fetus place higher value in the health and delivery of the male fetus than of the female, and hence selectively choose to travel to a hospital to deliver a male child. We now present analysis from the 9-month follow-up to illustrate correlates of access and use of ultrasound and women's knowledge of the sex of the fetus prior to the birth.

Column 3 in table 1 presents correlates of ultrasound conducted during antenatal period of the current birth, controlling for hospital and month fixed effects. Older women are more likely to have ultrasound conducted during the antenatal period of their current child, and ultrasound prevalence is higher among educated women compared with women with no schooling. Compared with Janajaati ethnic group, Hill Brahmins and Chhetris are more and Madhesis and Dalits are less likely to have conducted ultrasound. Women who report history of abortion are more likely to have conducted ultrasound for their current birth.

As discussed before, facilitating or conducting sex determination tests is illegal in Nepal. However, we find that $13 \%$ of the women in our follow-up sample report knowing the sex of their child before birth. Similar to correlates of male birth, women reporting knowledge of the sex of their fetus before birth is also correlated with women's education and parity with significant interactions between these covariates (table 1, column $5)$. Along the education gradient, an estimated $35 \%$ of women with at least secondary schooling at parity three or more report knowledge of the sex of their child before birth as compared with $18 \%$ of women with no schooling at the same category of parity (figure 3). Along the parity gradient, among women with at least secondary schooling, primiparous women are 25 percentage points less likely to report that they know the sex of their child before birth.

The estimated SRBs are remarkably different across women who report knowledge of sex of the current child before birth. Figure 4 illustrates SRB for women across parity, education groups and knowledge of the sex of the fetus. Consistently across all categories, we find that women who report that they know the sex of the fetus are more likely to give birth to a male child than a female child. For example, women who reported knowledge of the sex of fetus, with parity three or higher who have at 
Table 1 Association of sociodemographic factors with male births, ultrasound during antenatal care (ANC) and knowledge of sex of current child before birth in study hospitals

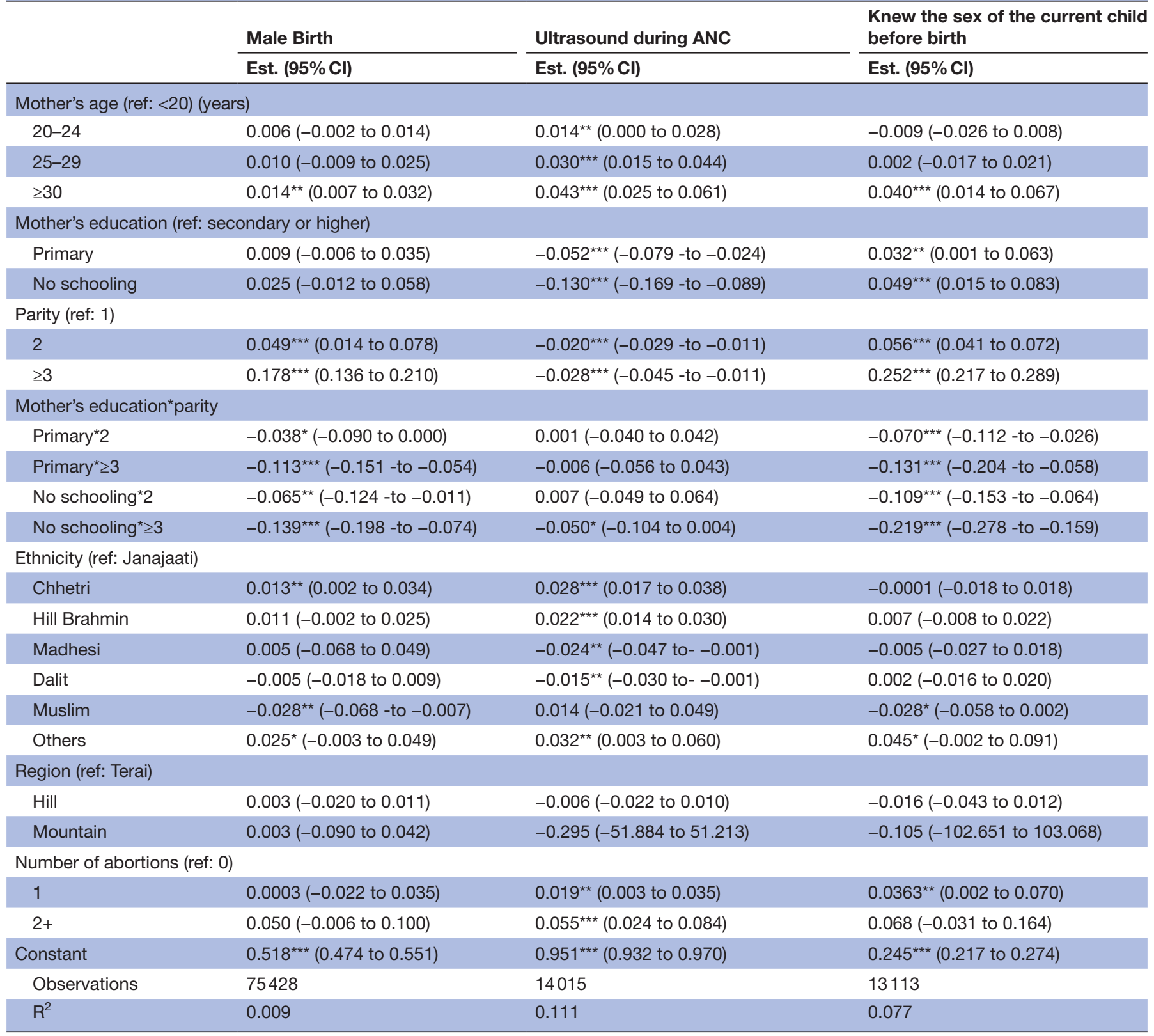

${ }^{*} \mathrm{P}<0.1,{ }^{* \star} \mathrm{P}<0.05,{ }^{* \star \star} \mathrm{P}<0.01$.

All regression models adjusted for hospital and month fixed effects. Difference from null tested using wild cluster bootstrap method.

least secondary schooling had 6.4 times as many boys than girls.

To further understand the interaction between parity and education, we subselect women having their second child and estimate the conditional SRB across women's educational groups differentiating between those who report having a living son from their first birth to those who do not (either the first-born was a daughter, or it was a son who has passed away) (figure 5). We find that the sex of the second birth is not significantly different from the biological SRB if women already have a living son, but women with any education tend to have a significantly higher number of sons in their second birth if they do not have a living son. Women with any schooling are estimated to have 1.7 times as many sons than daughters in our study hospital in their second birth if they do not have a living son.

The estimates observed in the analyses shown until now are based on surveys for which enrolment took place in study hospitals, and the sample only includes women who chose to give birth in those hospitals. In the analysis below, we compare our results on estimates of conditional SRB from the hospital sample with the nationally representative 2011 NDHS data. First, we compare the SRB of 


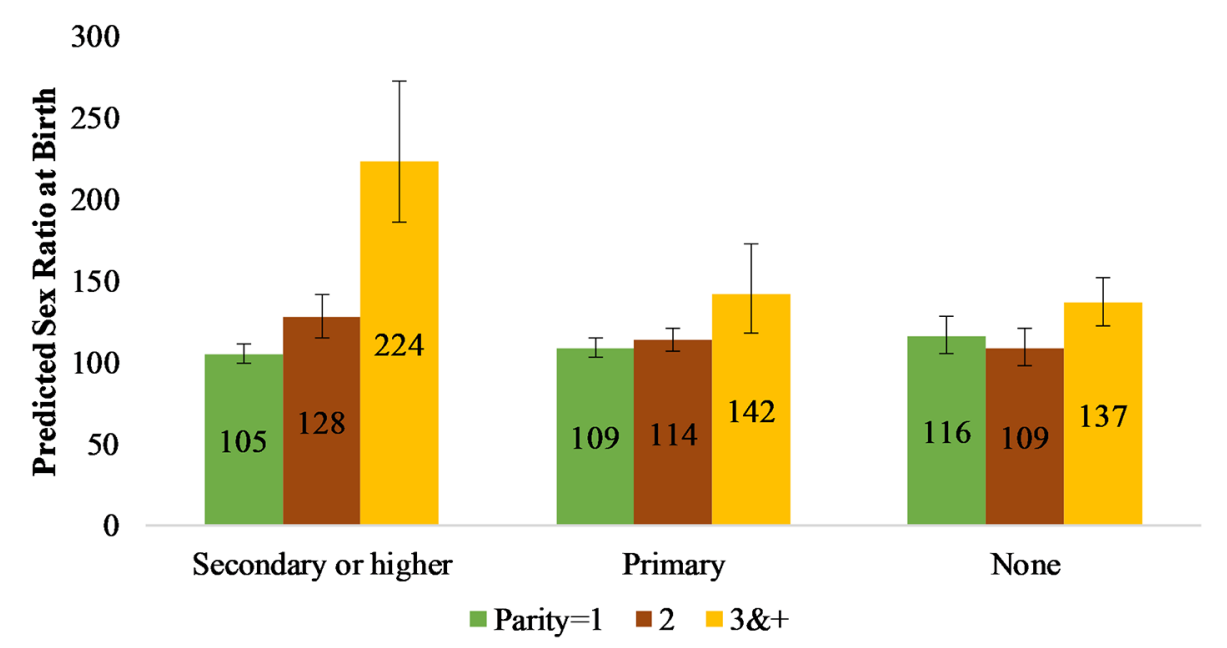

Note: Confidence intervals shown. Estimates adjusted for covariates as shown in model 1.

Figure 2 Predicted sex ratio at birth across women's education and parity.

second-order births for those without male siblings across study data and NDHS (figure 6). Similar to the hospital sample estimates, we find that the NDHS estimates of SRB of second-order births conditional on not having a living male sibling is significantly higher than biological SRB, at 150 male births per 100 female births.

In figure 7 , we illustrate any differentials in sex ratio of all births versus second-order births conditional on having an older sister, in analysis similar to Frost $e a^{11}$ using the nationally representative NDHS data. Compared with all births in the past 3 years, the sex ratio of second-order births with an older girl sibling is higher by 13 points-the SRB of second-order births who do not have a living male sibling is 132. Mothers with at least secondary schooling are much more likely to bear a son in the second birth conditional on not having a living son-on average, women with at least secondary schooling have 107 boys to 100 girls, but if they have a girl as a first born or if their first-born son has passed away, they are 1.5 times more likely to have a son rather than a daughter for their second child. Differences in SRB across first birth and conditional second birth also hold across the wealth quintile levels in the 2011 NDHS, although the differences are not statistically significant likely because of small sample size of the conditional SRB estimates.

We tabulate the results of stepwise regression associating male babies and hospital-based delivery adjusting for mother's sociodemographic characteristics in table 2. We find that boys are not more likely to be delivered in hospitals as compared with girls. As the corresponding data columns in table 2 show, the link between hospital-based births and sex of the child is not significant across the different levels of stepwise regression.

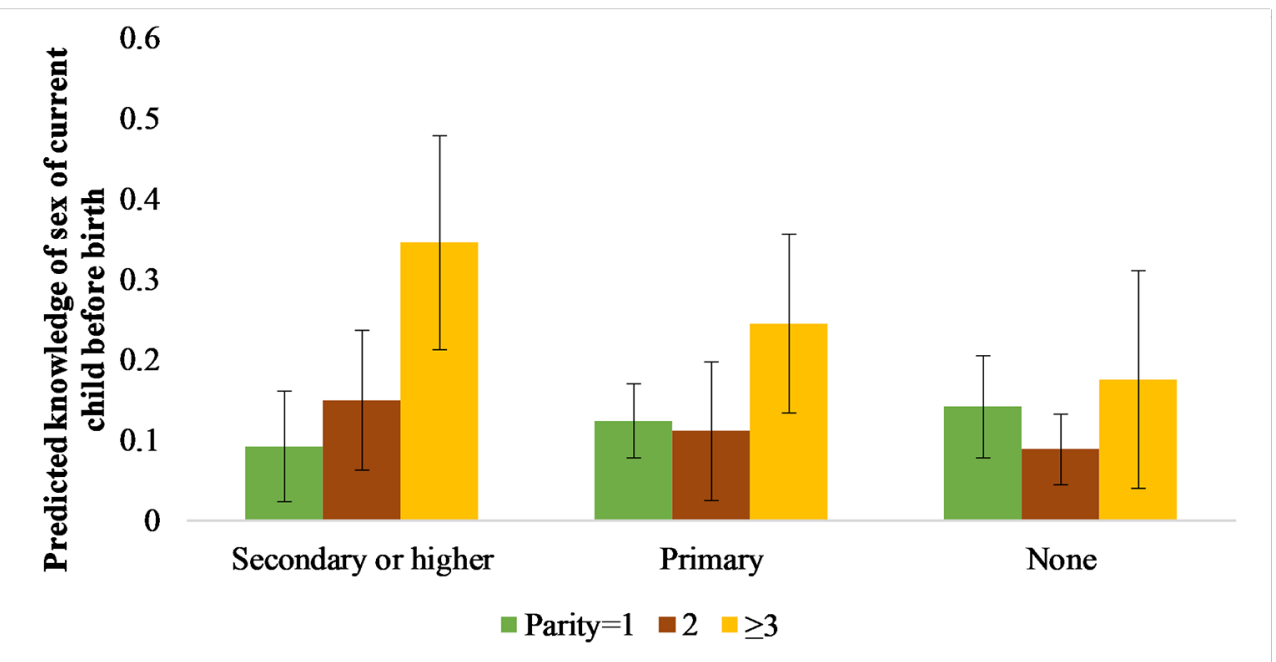

Note: Confidence intervals shown. Estimates adjusted for covariates as shown in model 3.

Figure 3 Predicted knowledge of sex of current child before birth across women's education and parity. 


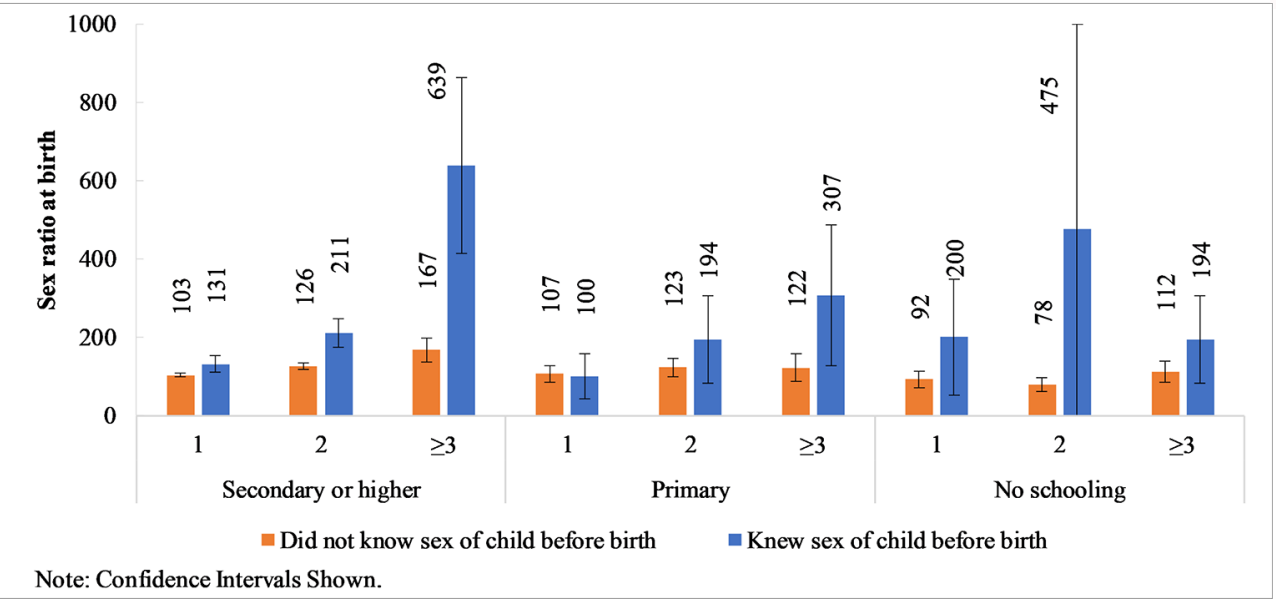

Figure 4 Sex ratio at birth across women's education, parity and knowledge of sex of child before birth.

\section{DISCUSSION}

Our analysis shows evidence of skewed sex ratio of deliveries in six large public hospitals in Nepal. Consistent with the literature on determinants of son preference and sex-selective abortion, we show that male birth in the study hospitals is correlated with higher parity births and higher education of mothers. Using the nationally representative NDHS, we also find that male babies are no more likely to be delivered in hospitals than female babies, adjusting for the mother's sociodemographic characteristics, which suggests sex-selective abortion as the primary reason behind skewed SRBs.

We find that more educated women and women having higher parity births are more likely to use sex-determination tests for the child. Similar to Frost $e t a l,{ }^{11}$ we show that the gender imbalance is higher in second-order births compared with all births in our study sample, and these differences are larger in more educated women and women from richer households. With increasing preference for smaller family size and persistent son preference, households face the pressure of balancing the sex of their children while having a small family size. Consistent with the literature from India discussed in the background section, women with more resources and more knowledge have greater access to ultrasound technologies, but the extent of use of these technologies for sex-selective abortion was dependent on sex composition of their children who were already born. ${ }^{5}$

We did not find male birth to be significantly correlated with the mother's abortion history. This could be interpreted in two ways. If the abortion reporting is accurate, then the skewed sex ratio in the hospital births could be attributed to the additional investment pathway, which is that the knowledge of the sex of the fetus led to the family delivering the male fetus in the hospital. However, abortion is often under-reported in which case male birth might be correlated with the true, but unknown, abortion history. In this case, the first pathway of female feticide is a likely explanation for skewed SRB. Families and women who have undergone sex-selective abortion may be

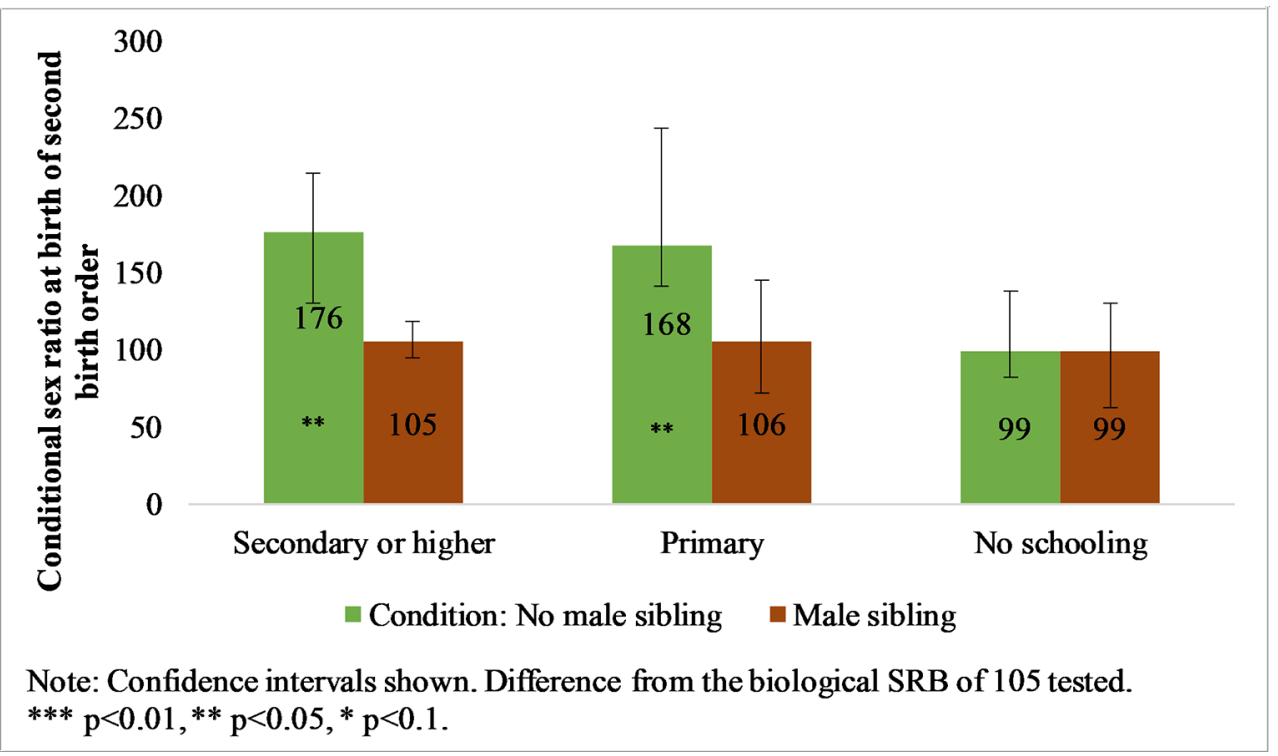

Figure 5 Sex ratio at birth (SRB) of second birth order across women's education and living male child. 


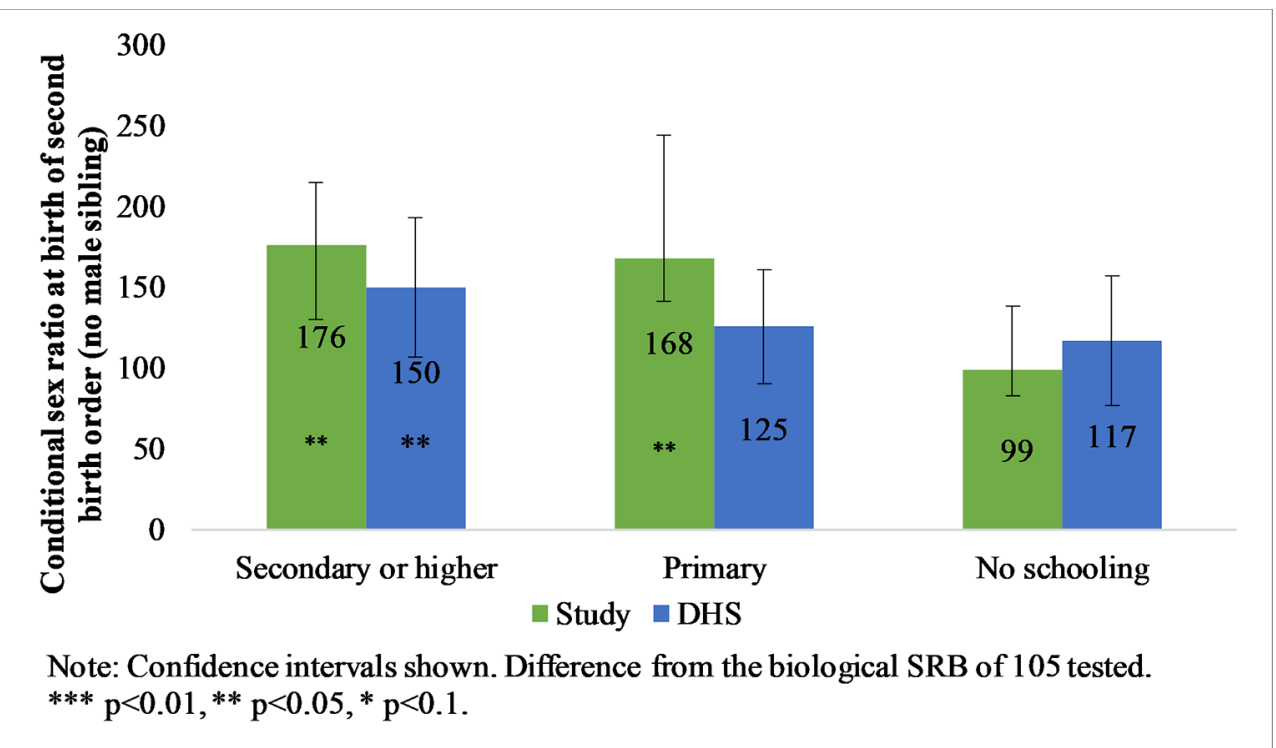

Figure 6 Conditional SRB of second-order birth with no male sibling, comparison between hospital sample (study) and Nepal DHS across education groups. DHS, Demographic and Health Survey.

differentially more likely to report that they do not have a history of induced abortion, in which case the estimate of abortion history on male birth will be an underestimate.

A major limitation of this study is potential reporting bias on key mediating parameters. Women are likely to under-report experience of induced abortion that could be an important explanatory link in understanding the skewed SRBs. Furthermore, even though $13 \%$ of the women in the survey reported knowing the sex of the child despite sex-determination tests being illegal in Nepal, the women who were conscious of the illegal nature of the tests could have chosen to not report that they conducted in utero sex-determination tests for their current birth. Hence, the knowledge of the sex of the current birth before delivery could also be under-reported.

Another potential limitation of the study is that there is considerable loss to follow-up for the sample that the prenatal sex knowledge questions are derived from. However, comparison of the covariates between the full sample and the follow-up sample (online supplementary appendix table 1) shows that women in the two samples have about the same distribution of age, educational levels, parity, male births and history of induced abortions.

Our hospital-based study is focused on women who gave birth in health facilities in Nepal, and this sample is selective and might not be representative of all births nationally, as $57 \%$ of all live births in five years preceding the 2016 DHS took place in a health facility. ${ }^{25}$ Additionally, $81 \%$ of women in our hospital-based sample had at least secondary schooling, whereas only $48 \%$ of the women in the 2011 DHS sample had at least secondary schooling - the women in our sample are more educated, younger and have fewer children than the women in the nationally representative NDHS. This phenomenon of skewed SRB could be localised to younger and more educated mothers, which would be analogous to findings from other countries where skewed SRBs are reported. ${ }^{135}$

Although from a selected sample, we contribute to the literature by reporting on skewed SRB in Nepal across sociodemographic characteristics, using a large sample that accounts for about $20 \%$ of all births in Nepal during the study period. We find that women's education, which is a proxy variable for measuring access to health services (mainly knowledge), and parity are important correlates of male births and reports of sex-determination tests. Although comprising only hospital births, this striking phenomenon covers $20 \%$ of all births in Nepal during the year and a half of the survey period; the large sample size also adds to the significance and validity of our results. Comparing conditional SRBs in nationally representative NDHS and in the hospital sample, we find that SRB for all births (not only hospital births) was significantly higher for second-order births if the first-order birth was a girl, which suggests the sex-selective abortion pathway. Additional findings on: (1) women reporting knowledge of the sex of the fetus and significantly differential SRBs across the socioeconomic groups and (2) no correlation of male births with facility deliveries using the nationally representative sample further support the sex-selection abortion pathway.

The Trivers-Willard effect would be consistent with more educated and wealthy women having more sons as they are generally in better health condition. ${ }^{21}$ However, figure 5, which illustrates SRBs for second-order births differentially among those with male siblings and no male siblings suggest that sociological son preference is still overwhelmingly the primary reason for skewed SRBs among educated women-the conditional SRB of second-order births with male siblings among women with at least secondary schooling is 105 , as compared with 176 for those without any male siblings. 


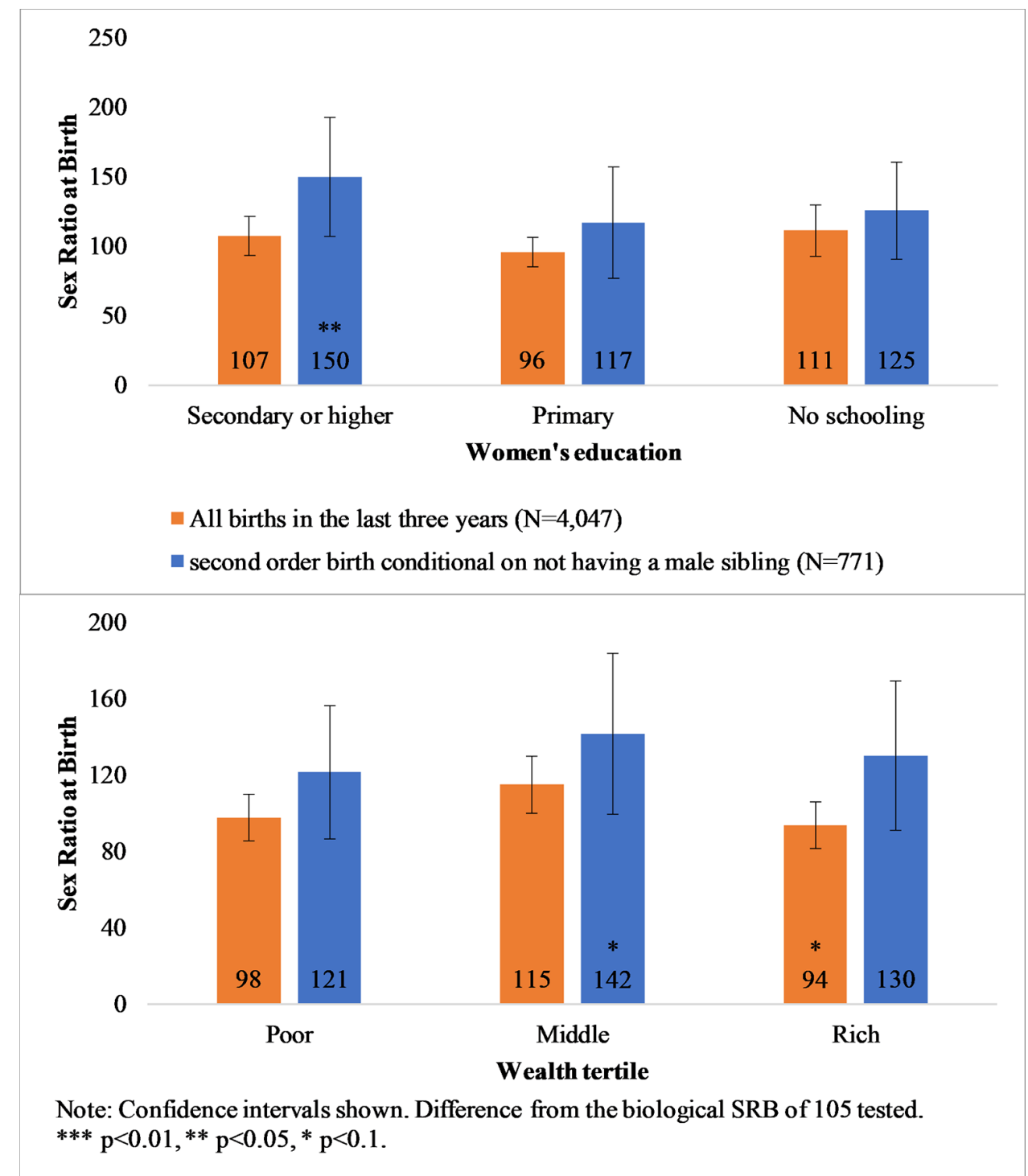

Figure 7 Sex ratio at birth (SRB) across sociodemographic characteristics between all births in the last 3 years and secondorder births conditional on having an older sister.

Nepal has seen a rapid decline in actual and desired fertility rates over the last 40 years. However, the reduction in desired fertility exists in a society with persistent preferences for a son, because of cultural and religious norms, and economic rationale. Aside from the religious norms such as sons being necessary to perform death rituals in Hinduism, parents have an economic incentive to have sons in an environment where: (1) strong filial (social and financial) ties exist between parents and children, (2) women are not able to realise their full economic earning potential and (3) daughters are considered to 'belong' to another family after marriage. The marginalised status of women, coupled with increasing access to sex-selection technology and lack or weak enforcement of the law is further skewing SRBs in Nepal.

Imbalanced SRBs are not immutable as evidenced from South Korea. SRBs in South Korea rose from 109 in 1985 to 115 in 1994, but then declined reaching 105 in 2016. ${ }^{26}$ Most remarkable are the 2016 SRB figures by birth order-104 for the first-order births, 105 for the second and 107 for the (fewer) third or higher order births. This transition to balanced SRB has been achieved by a combination of factors resulting in raising the status and empowerment of women. ${ }^{27}$ Increased opportunities for higher education and better employment contributed to women's autonomy coupled with laws and policies addressing women's rights. The law recognising women's inheritance and other rights within their birth family following marriage contributed to redressing the traditional gender imbalance that existed in Korea. Media campaigns such as 'Love your daughters' and other measures such as strict enforcement of laws prohibiting the misuse of technology for sex determination, increased exposure to mass media, weakening of traditional patrilineal norms with increasing urbanisation and industrialisation and expansion of nuclear families all contributed to bringing down SRB to the normal biological level in the country. ${ }^{28-30}$ As exemplified by the South Korean 


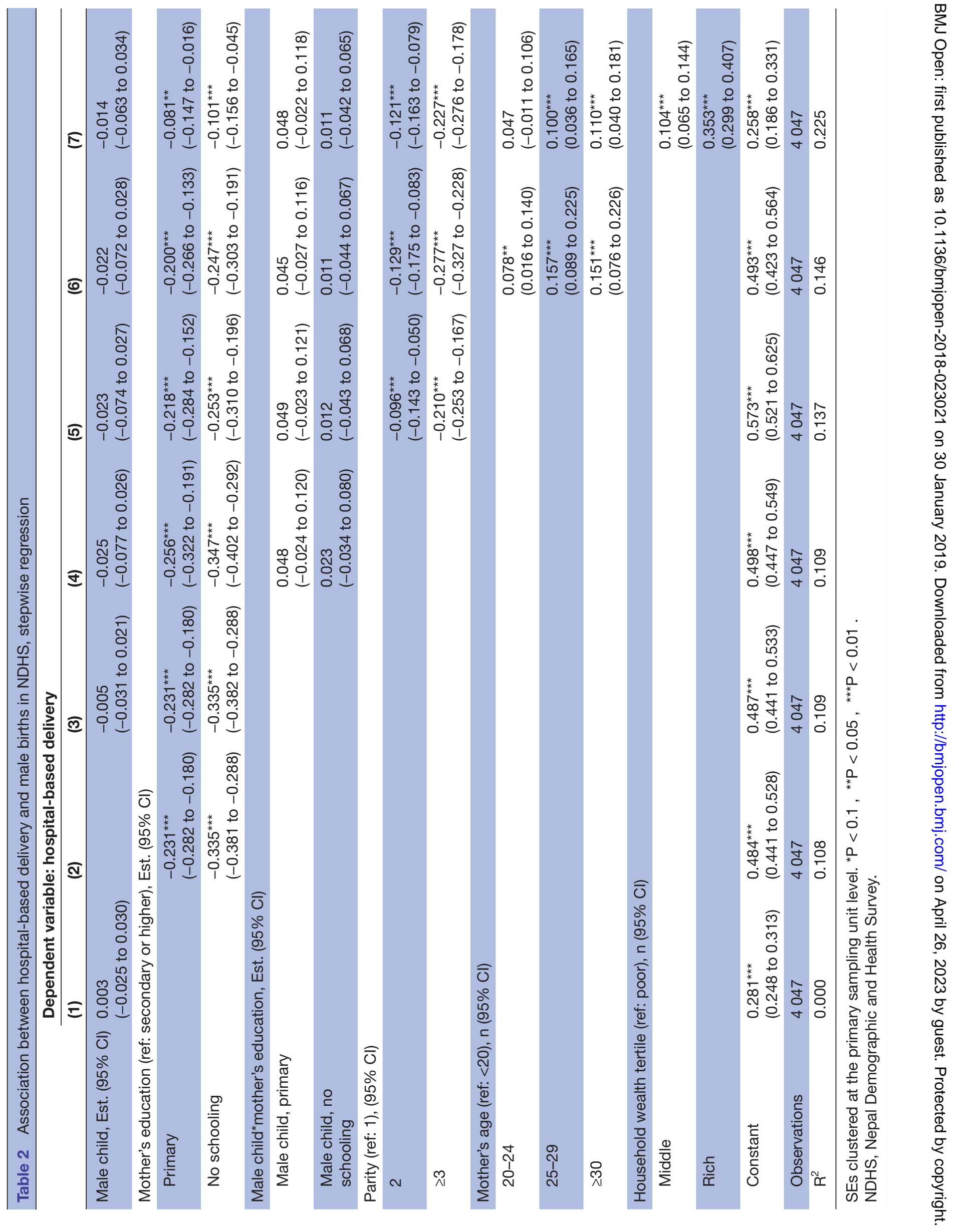


experience, it is possible to bring down the skewed SRB to the normal level by systematic and multipronged efforts.

Bongaarts and Guilmoto ${ }^{31}$ predict that the preference for sons and gender discriminations faced by the female sex from before birth that continues over a lifetime has manifested as three million excess female deaths every year globally or 150 million missing women by $2035 .{ }^{31}$ Our findings highlight the marginalised status of women in Nepal and stress the urgent need for research and implementation of policies that reduce son preference and, ultimately, skewed sex ratios. National strategies to prevent misuse of ultrasound services and gender-biased sex selection that do not hinder women's access to safe abortion services are needed. Most importantly, comprehensive interventions with a mix of laws, policies and advocacy campaigns that aim to improve the status of women and eliminate gender-based discrimination are needed to achieve a balanced SRB and subsequent survival and quality of life.

Correction notice Since this paper was first published online, typographical errors have been amended in the text which were generated due to a software error.

Acknowledgements The analysis in this study is made possible with the time and effort by the women in the PPIUD project who participated in the research study about a day after giving birth. The authors would like to thank these women and the thousands of women who took their time in participating in the 2011 Nepal Demographic and Health Survey (DHS). We would also like to acknowledge the valiant effort from thousands of enumerators and program staff in the DHS and PPIUD project. We are grateful to Nepal Society of Obstetricians and Gynaecologists and International Federation of Obstetricians and Gynaecologists for implementing the intervention in the parent study that the paper is based on.

Contributors EPr and EPe analysed the data and wrote the first draft of the manuscript. MP serves as principal investigator of the parent study. All authors contributed to the development or revision of study instrument or reviewed the manuscript and provided scientific oversight. EPr, EPe, MP and IS read, edited and approved the final manuscript.

Funding This study was funded by a grant to the Harvard T.H. Chan School of Public Health from the Susan Thompson Buffett Foundation.

Disclaimer The findings, interpretations, and conclusions expressed in this paper are entirely those of the authors. They do not necessarily represent the views of the organizations involved. The funding source had no role in the design, implementation, data collection, analysis and interpretation of results or in dissemination of findings.

Competing interests None declared.

Patient consent for publication Not required.

Provenance and peer review Not commissioned; externally peer reviewed.

Data sharing statement Availability of data and materials: the DHS data are available from the DHS programme website. A sample of data from the parent longitudinal study will be made available for replication study on request. The entire data set will also be made public at the end of the study. All data requests should be sent to the Program Coordinator Laura Campagna at Icampagn@hsph.harvard. edu.

Open access This is an open access article distributed in accordance with the Creative Commons Attribution Non Commercial (CC BY-NC 4.0) license, which permits others to distribute, remix, adapt, build upon this work non-commercially, and license their derivative works on different terms, provided the original work is properly cited, appropriate credit is given, any changes made indicated, and the use is non-commercial. See: http://creativecommons.org/licenses/by-nc/4.0/.

\section{REFERENCES}

1. Guilmoto CZ. The sex ratio transition in Asia. Popul Dev Rev 2009;35:519-49.
2. Bélanger D, Thi Hai Oanh $\mathrm{K}$, Jianye L, et al. Les rapports de masculinité à la naissance augmentent-ils au Vietnam ? Population 2003;58:255.

3. Parazzini F, La Vecchia C, Levi F, et al. Trends in male:female ratio among newborn infants in 29 countries from five continents. Hum Reprod 1998;13:1394-6.

4. Bank W. World Bank. World Development Indicators. Washington, D.C, 2017.

5. Attane I. Watering the neighbour's garden: the growing demographic female deficit in Asia. $2007 \mathrm{http}: / /$ agris.fao.org/agrissearch/search.do?recordID=XF2015028131 (Accessed 28 Sep 2016).

6. Gupta MD, Chung W, Shuzhuo L. Evidence for an incipient decline in numbers of missing girls in China and India. Popul Dev Rev 2009;35:401-16.

7. Bhat PNM, Zavier AJF. Factors Influencing the Use of Prenatal Diagnostic Techniques and the Sex Ratio at Birth in India. Econ Polit Wkly 2007;42:2292-303.

8. Urquia ML, Moineddin $\mathrm{R}$, Jha $\mathrm{P}$, et al. Sex ratios at birth after induced abortion. CMAJ 2016;188:E181-90.

9. Leone T, Matthews Z, Dalla Zuanna G. Impact and determinants of sex preference in Nepal. Int Fam Plan Perspect 2003;29:69-75.

10. Grech V. Gendercide and femineglect. Early Hum Dev 2015;91:851-4.

11. Frost MD, Puri M, Hinde PR. Falling sex ratios and emerging evidence of sex-selective abortion in Nepal: evidence from nationally representative survey data. BMJ Open 2013;3:e002612.

12. Puri M, Tamang A. Understanding factors influencing adverse sex ratios at birth and exploring what works to achieve balance: the situation in selected districts of Nepal. Kathmandu, Nepal: CREHPA, 2015.

13. Government of Nepal. National safe abortion service policy. B.S, 2060.

14. Lamichhane P, Harken T, Puri M, et al. Sex-selective abortion in Nepal: a qualitative study of health workers' perspectives. Womens Health Issues 2011;21:S37-S41.

15. Ministry of Health and Population (MOHP) [Nepal], New ERA, and Macro International Inc. Nepal demographic and health survey 2011. Kathmandu, Nepal: Ministry of Health and Population, New ERA, and Macro International Inc, 2012.

16. Canning D, Shah IH, Pearson E, et al. Institutionalizing postpartum intrauterine device (IUD) services in Sri Lanka, Tanzania, and Nepal: study protocol for a cluster-randomized stepped-wedge trial. BMC Pregnancy Childbirth 2016;16:362.

17. Jha P, Kumar R, Vasa P, et al. Low male-to-female sex ratio of children born in India: national survey of 1.1 million households. The Lancet 2006;367:211-8.

18. Jha P, Kesler MA, Kumar R, et al. Trends in selective abortions of girls in India: analysis of nationally representative birth histories from 1990 to 2005 and census data from 1991 to 2011. Lancet 2011;377:1921-8.

19. Fukuda M, Fukuda K, Mason S, et al. The sex ratio at birth after recent major earthquakes in Japan. Early Hum Dev 2018;123:30-1.

20. Bertrand M, Duflo E, Mullainathan S. How much should we trust differences-in-differences estimates? Q J Econ 2004;119:249-75.

21. Cameron AC, Gelbach JB, Miller DL. Bootstrap-based improvements for inference with clustered errors. Rev Econ Stat 2008;90:414-27.

22. Webb MD. Reworking wild bootstrap based inference for clustered errors. Queen's University, Department of economics. 2014 https:// ideas.repec.org/p/qed/wpaper/1315.html (Accessed 16 Dec 2016).

23. Roodman D. BOOTTEST: Stata module to provide fast execution of the wild bootstrap with null imposed. Boston College Department of Economics. 2016 https://ideas.repec.org/c/boc/bocode/s458121. html (Accessed 16 Dec 2016).

24. Central Bureau of Statistics. Population monograph of Nepal. Kathmandu, Nepal: National Planning Commission Secretariat, Government of Nepal, 2014.

25. Ministry of Health, Nepal New ERA, ICF. Nepal demographic and health survey 2016. Kathmandu, Nepal: Ministry of Health, Nepal, 2017.

26. Korea S. Republic of Korea. Korean statistical information service. http://kosis.kr/eng/ (Accessed 12 Jan 2018).

27. Chung W, Gupta MD. The Decline of Son Preference in South Korea: the roles of development and public policy. Popul Dev Rev 2007:33:757-83.

28. Park CB, Cho N-H. Consequences of Son Preference in a LowFertility Society: Imbalance of the Sex Ratio at Birth in Korea. Popul Dev Rev 1995;21:59-84.

29. Hesketh T, Lu L, Xing ZW. The consequences of son preference and sex-selective abortion in China and other Asian countries. CMAJ 2011;183:1374-7. 
30. Chun H, Das Gupta M. Gender discrimination in sex selective abortions and its transition in South Korea. Womens Stud Int Forum 2009;32:89-97.
31. Bongaarts J, Guilmoto CZ. How many more missing women? Excess female mortality and prenatal sex selection, 1970-2050. Popul Dev Rev 2015;41:241-69. 